\title{
INTEGRABILITY THEOREMS FOR FOURIER-JACOBI TRANSFORMS
}

\section{CHOKRi ABDELKEFI AND ABDESSATtAR JEMAI}

Abstract. In this paper, we prove the Hardy-Littlewood-Paley inequality for the generalized Fourier transform on Chébli-Trimèche hypergroups and we study in the particular case of the Jacobi hypergroup the integrability of this transform on Besov-type spaces.

Mathematics subject classification (2010): Primary 47G30, Secondary 44A15, 44A35.

Keywords and phrases: Chébli-Trimèche hypergroups; Generalized Fourier transform; Jacobi hypergroup; Jacobi function.

\section{REFERENCES}

[1] C. AbDelKefi And M. SIFI, On the uniform convergence of partial Dunkl integrals in Besov-Dunkl spaces, Fractional Calculus and Applied Analysis Vol. 9, N. 1 (2006), 43-56.

[2] C. Abdelkefi AND M. SifI, Characterization of Besov spaces for the Dunkl operator on the real line, Journal of Inequalities in Pure and Applied Mathematics, Vol. 8 (2007), Issue 3, Article 73, 11 pp.

[3] C. AbdelKefi AND M. Sifi, Further results of integrability for the Dunkl transform, Communication in Mathematical Analysis Vol. 2, N. 1 (2007), 29-36.

[4] C. Abdelkefi, J. PH. AnKer, F. SASsi And M. Sifi, Besov-type spaces on $\mathbb{R}^{d}$ and integrability for the Dunkl transform, Symmetry, Integrability and Geometry: Methods and Applications, SIGMA 5 (2009), 019, 15 pages.

[5] O. V. Besov, On a family of function spaces in connection with embeddings and extentions, Trudy Mat. Inst. Steklov 60 (1961), 42-81.

[6] W. R. Bloom AND H. HeYeR, Harmonic analysis of probability measures on hypergroups, Walter de Gruyter Berlin-NewYork, 1995.

[7] W. O. BRAY AND M. A. Pinsky, Growth properties of Fourier transform via moduli of continuity, J. Funct. Anal. 255 (2008) 2265-2285.

[8] W. O. BRAY AND M. A. PINS KY, Growth properties of the Fourier transform, arXiv: 0910.1115v1 [math.CA] 6 Oct 2009.

[9] T. H. KOORNWINDER, Jacobi functions and analysis on non compact semisimple Lie groups. Special Functions: Group Theoretical Aspects and Applications, (R. A. Askey, T. H. Koornwinder and W. Schempp, eds.) Reidel, Dordrecht, 1984.

[10] E. C. TitchmaRSH, Introduction to the theory of Fourier integrals, Clarendon Press, Oxford, 1937.

[11] K. Trimèche, Generalized Harmonic Analysis and Wavelets Packets, Gordon and Breach Science Publishers (1997).

[12] K. TRImèche, Transformation intégrale de Weyl et Théorème de Paley-Wiener associés à un opérateur différentiel singulier sur $(0,+\infty)$, J. Math. Pure et Appl., 60, pp. 51-98, 1981. 